\title{
Sensitivity Analysis of Workspace Conflicts According to Changing Geometric Conditions
}

\author{
Mohammad Rohani \\ Faculty of Civil Engineering \\ Semnan University \\ Seman, Iran \\ M.Rohani@ \\ students.semnan.ac.ir
}

\author{
Gholamali Shafabakhsh \\ Faculty of Civil Engineering \\ Semnan University \\ Seman, Iran \\ shafabakhsh@, \\ semnan.ac.ir
}

\author{
Abdolhosein Haddad \\ Faculty of Civil Engineering \\ Semnan University \\ Seman, Iran \\ ahadad@ \\ semnan.ac.ir
}

\author{
Ehsan Asnaashari \\ Faculty of Civil Engineering \\ Alaodole Semnani Institute \\ Seman, Iran \\ asnaashari.ehsan@ \\ gmail.com
}

\begin{abstract}
Workspace conflicts and building components can happen in different forms and both permanently and temporarily. These spatial clashes affect the work process and deplete the project process. Geometric clash detection system of 4D simulation tools can identify the number of clashes for construction resources in the worksite to improve workflow planning. In the present research, building components and their corresponding workspaces were simulated, based on the schedule and activities, using a visual simulation tool. First, the total daily volumes of workspace were calculated according to the activities' schedule and compared by the available space in order to determine the critical days for the project. Then, the number of time-based conflicts were examined and analyzed for building components and resources among activities and by different tolerance distances. The main objective of this study was to evaluate the sensitivity analysis of clash numbers based on the geometrical conditions in different statuses (Inflexible, Semiflexible and flexible) to assist the planner for detecting real conflicts. The results show that the tolerance distance of 0.2 to 1 meter for the clashes of workspace and the building components and 0.2 to 2 meters for the clashes of workspaces with each other to provide realistic results of actual construction operation conflicts. By the help of this methodology, the project planners are able to identify and prioritize the effective conflicts on the work process in comparison to the clashes resulted from iteration or minor design inaccuracy.
\end{abstract}

Keywords-building components; construction workspace; geometrical clashes; tolerance distance

\section{INTRODUCTION}

Time and cost management without investigating the required workspace for the execution of activities would not only be unrealistic, but also they can have additional consequences on projects costs. The required space for activities like the required resources for implementing activities, must be managed by planning and scheduling. The lack of the management for the required space for activities by conventional planning and scheduling techniques leads to the time-space conflicts [1], in which the required space of one activity is interrupted with the space required by another activity or workspace. In this regard, multi-dimensional CAD models significantly help in identifying and resolving this conflict $[2,3]$, however, some problems are prevented from achievement. The first issue in developing these models is related to the capability of dynamic presentation $[4,5]$. As the project site location is a dynamic one, each of the construction activities have their own workspace that are reformed by time. An activity can occupy different spaces in different stages of construction [6]. Actually a simple 3D form in visual simulation of process cannot be used to present the workspace dynamics of the construction activities [7]. Usually, "3D CAD" models are used as the occupied space by building components and put other required workspaces aside. As a result, the CAD models are not able to present realistic visualization of construction process [5]. Therefore, the planners and project managers should collect and integrate the fragmented time and space information from different sources to display the project workspaces and the workflow of construction operation manually [8].

On the other hand, the progress of other fields such as Information Technology has affected the development of engineering and construction tools. This development has caused Building Information Modelling (BIM) to be one of the encouraging developments in Architecture, Engineering and Construction (AEC) sector [9, 10]. By BIM based tools, visualization and simulation technologies and project management knowledge, the project planning and controlling can be performed with a better perspective and the information gaps of the projects that have huge financial and time consequences can be solved [11]. The construction industry needs a workspace model, in which the building components and the spaces required by working teams are merged, but this is not possible without the consideration of workspace details. Despite the dynamism and changes of the workspaces required for activities over a period of time, these spaces still follow a distinct evolutionary process in most construction activities [6]. An ideal 4D construction planning system should be capable of dynamic presentation and be able to model and present dynamic elements and components acceptably [9, 12]. This study, providing the space for one day of work performance 
and simulation based on time to enable the planners for understanding of the real conditions of work progress and possible clashes of them. Different types of clashes and their intervals can help planners in identification and prioritization of the important conflicts [13].

\section{RESEARCH METHODOLOGY}

This investigation is initiated by converting $2 \mathrm{D}$ drawings of buildings to 3D building components in a design software. Next, the workspaces of one day's work which is correspond with each of the building components were designed and generated in the form of $3 \mathrm{D}$ volumes based on construction resources analysis. By using BIM based tools (4D CAD software) like Naviswork Manage [14], 3D volumes corresponding with the workspaces of resources (temporary appearance) and building components (permanent appearance) were visualized and simulated based on the schedule. The workspaces were designed according to the building component axis and for one day segments and the volumes were automatically estimated. The total amount of workspaces required for working teams and construction resources were estimated based on a schedule on a daily basis. Then, this estimated daily volumes were compared to the total available space of each floor (level) to determine the days with critical space.
Finally, the time-based simulation is assessed in hard mode and with specific different distances to compare and analyze the resulted clashes in different intervals. These volume clashes have occurred between activities and in three general types: building components and workspaces, building components with each other and workspaces with each other. This system is of great help to the identification of clashes and appropriate intervals for any kind of clashes. In this way, the planners are able to identify and detect the effective workspace conflicts on the work process from the clashes resulted from iteration or design inaccuracy.

\section{THE QUANTITY OF WORKSPACES}

By analyzing the construction resources, the required workspace for each of the activities is calculated and designed. Considering that in the case study of 12 defined activities, only 9 activities were active. The space properties for each of the building components are estimated based on the square meter and meter length of the drawings and 3D volumes automatically and are presented in Table I. Also, the workspace volumes for the activities resources are specified in the mentioned table in total and in average. These volumes were created by automatic estimation of spaces in Google sketchup software, in which all of the specifications of the considered component is inserted.

TABLE I. TABLE OF QUANTITIES AND VOLUMES OF BUILDING COMPONENTS AND WORKSPACE

\begin{tabular}{|c|c|c|c|c|c|}
\hline Activity Name \& No. & Duration & $\begin{array}{c}\text { Component } \\
\text { Quantity }\left(\mathrm{m}^{2} \& \mathrm{ml}\right) \\
\end{array}$ & $\begin{array}{c}\text { Average of } \\
\text { Component }\left(\mathrm{m}^{2} \& \mathrm{ml}\right) \\
\end{array}$ & Workspace $\left(\mathrm{m}^{3}\right)$ & $\begin{array}{l}\text { Daily Average of } \\
\text { Workspace }\left(\mathrm{m}^{3}\right)\end{array}$ \\
\hline 1.Project Total & 60 & - & - & 2372 & - \\
\hline 2. Basement Structure & 0 & 0 & 0 & - & - \\
\hline 3. External Wall & 15 & 418.2 & 27.9 & 1743.3 & 116.2 \\
\hline 4. Windows Frames & 12 & 1032 & 129 & 1009.8 & 84.2 \\
\hline 5. Interior Wall & 12 & 316.3 & 26.4 & 1640 & 136.7 \\
\hline 6. Gypsum Plastering & 12 & 480.8 & 40.1 & 790.8 & 65.9 \\
\hline 7. Concrete Base & 8 & 678 & 84.8 & 1882 & 235.3 \\
\hline 8. Ceramic Tile & 25 & 678 & 27.1 & 2404.8 & 96.2 \\
\hline 9.Fan coil Unit \& Piping & 5 & 53.4 & 10.7 & 555.9 & 111.2 \\
\hline 10. Cable Tray & 3 & 87 & 29 & 631.5 & 210.5 \\
\hline 11.Fabric-mate Ceiling & 18 & 678 & 37.7 & 3640.3 & 202.2 \\
\hline
\end{tabular}

Considering that the examined case study of this research is in floor level and the available space of construction is specified and limited, the volumes of construction resources are placed daily and base on schedule to determine the required space of each day. The volumes of the designed workspace are compiled daily base on schedule to determine the required space of the construction resources for each day and compare with the maximum available space [15] ( (1)). The available space of each floor level for each day is 2372 cubic meters that is much higher than the maximum required space of the projects days. Total space required for each day is varied from 50 to 584 cubic meters and it was at its highest level from day $37^{\text {th }}$ up to day $42^{\text {th }}$ (Table II). Also, the maximum required space is for the $40^{\text {th }}$ day with 584 cubic meters that is lower than the available space of each level (floor) and it has worked, but the final number of spatial clashes is determined by $4 \mathrm{D}$ simulation.
Available Space $\geq$ Daily Required (Needed) space (1)

\section{DEVELOPMENT OF WORKSPACE FOR CONSTRUCTION RESOURCES}

The most important factor in spatial formation and shaping is the final building component and the linear axis of these elements. The geometrical transparent volumes correspond to workspaces were formed along these lines and in the two dynamic and static categories [16]. The dynamic and static workspaces were created in parallel with components lines and in coordination with its development (Figure 1). On the other side, the classification of the construction methods is a great help in organizing and configuration of the workspaces in the worksite [17]. Therefore, geometric volumes were generated for activities in each day of project by utilizing resource analysis, construction methods classification and the building components axis. 
TABLE II. TOTAL DAILY AND SCHEDULE BASED REQUIRED VOLUMES OF THE CONSTRUCTION RESOURCES

\begin{tabular}{|c|c|c|c|c|c|c|c|c|c|c|}
\hline $\begin{array}{l}\text { Days } \\
\text { No. }\end{array}$ & $\begin{array}{c}\text { Act. } \\
3\end{array}$ & $\begin{array}{c}\text { Act. } \\
4\end{array}$ & $\begin{array}{c}\text { Act. } \\
5\end{array}$ & $\begin{array}{c}\text { Act. } \\
6\end{array}$ & $\begin{array}{c}\text { Act. } \\
7\end{array}$ & $\begin{array}{c}\text { Act. } \\
8\end{array}$ & $\begin{array}{c}\text { Act. } \\
9\end{array}$ & $\begin{array}{c}\text { Act. } \\
10\end{array}$ & $\begin{array}{c}\text { Act. } \\
11\end{array}$ & $\begin{array}{l}\text { Daily required } \\
\text { Space }(\mathrm{m} 3)\end{array}$ \\
\hline DAY1 & 99 & & & & & & & & & 99 \\
\hline DAY2 & 125 & & & & & & & & & 125 \\
\hline DAY3 & 161 & & & & & & & & & 161 \\
\hline DAY4 & 160 & & & & & & & & & 160 \\
\hline DAY5 & 123 & 83 & & & & & & & & 206 \\
\hline DAY6 & 99 & 85 & & & & & & & & 184 \\
\hline DAY7 & 110 & 85 & & & & & & & & 195 \\
\hline DAY8 & 99 & 83 & & & & & & & & 182 \\
\hline DAY9 & 111 & 83 & & & & & & & & 195 \\
\hline DAY10 & 111 & 84 & & & & & & & & 195 \\
\hline DAY11 & 115 & 85 & & & & & & & & 200 \\
\hline DAY12 & 111 & 85 & & & & & & & & 196 \\
\hline DAY13 & 111 & 85 & 212 & & & & & & & 408 \\
\hline DAY14 & 99 & 85 & 170 & & & & & & & 354 \\
\hline DAY15 & 107 & 83 & 94 & & & & & & & 285 \\
\hline DAY16 & & 84 & 121 & & & & & & & 205 \\
\hline DAY17 & & & 146 & & & & & & & 146 \\
\hline DAY18 & & & 149 & & & & & & & 149 \\
\hline DAY19 & & & 142 & & & & & & & 142 \\
\hline DAY20 & & & 149 & & & & & & & 149 \\
\hline DAY21 & & & 96 & & & & & & & 96 \\
\hline DAY22 & & & 131 & & & & & & & 131 \\
\hline DAY23 & & & 110 & & & & & & & 110 \\
\hline DAY24 & & & 119 & & & & & & & 119 \\
\hline DAY25 & & & & 61 & & & 81 & 230 & & 372 \\
\hline DAY26 & & & & 58 & & & 117 & 234 & & 409 \\
\hline DAY27 & & & & 50 & & & 110 & 168 & & 328 \\
\hline DAY28 & & & & 74 & & & 143 & & & 217 \\
\hline DAY29 & & & & 51 & & & 106 & & & 157 \\
\hline DAY30 & & & & 50 & & & & & & 50 \\
\hline DAY31 & & & & 60 & & & & & & 60 \\
\hline DAY32 & & & & 61 & & & & & & 61 \\
\hline DAY33 & & & & 88 & & & & & & 88 \\
\hline DAY34 & & & & 90 & & & & & & 90 \\
\hline DAY35 & & & & 88 & 219 & & & & & 306 \\
\hline DAY36 & & & & 60 & 242 & 81 & & & & 382 \\
\hline DAY37 & & & & & 236 & 111 & & & 194 & 541 \\
\hline DAY38 & & & & & 252 & 83 & & & 202 & 537 \\
\hline DAY39 & & & & & 252 & 78 & & & 193 & 522 \\
\hline DAY40 & & & & & 228 & 151 & & & 204 & 584 \\
\hline DAY41 & & & & & 246 & 86 & & & 151 & 482 \\
\hline DAY42 & & & & & 207 & 65 & & & 156 & 429 \\
\hline DAY43 & & & & & & 86 & & & 216 & 303 \\
\hline DAY44 & & & & & & 94 & & & 241 & 334 \\
\hline DAY45 & & & & & & 121 & & & 276 & 397 \\
\hline DAY46 & & & & & & 94 & & & 286 & 380 \\
\hline DAY47 & & & & & & 94 & & & 207 & 301 \\
\hline DAY48 & & & & & & 121 & & & 233 & 354 \\
\hline DAY49 & & & & & & 94 & & & 152 & 245 \\
\hline DAY50 & & & & & & 90 & & & 144 & 235 \\
\hline DAY51 & & & & & & 117 & & & 191 & 308 \\
\hline DAY52 & & & & & & 90 & & & 214 & 305 \\
\hline DAY53 & & & & & & 57 & & & 186 & 243 \\
\hline DAY54 & & & & & & 134 & & & 193 & 327 \\
\hline DAY55 & & & & & & 83 & & & & 83 \\
\hline DAY56 & & & & & & 79 & & & & 79 \\
\hline DAY57 & & & & & & 80 & & & & 80 \\
\hline DAY58 & & & & & & 94 & & & & 94 \\
\hline DAY59 & & & & & & 128 & & & & 128 \\
\hline DAY60 & & & & & & 96 & & & & 96 \\
\hline
\end{tabular}




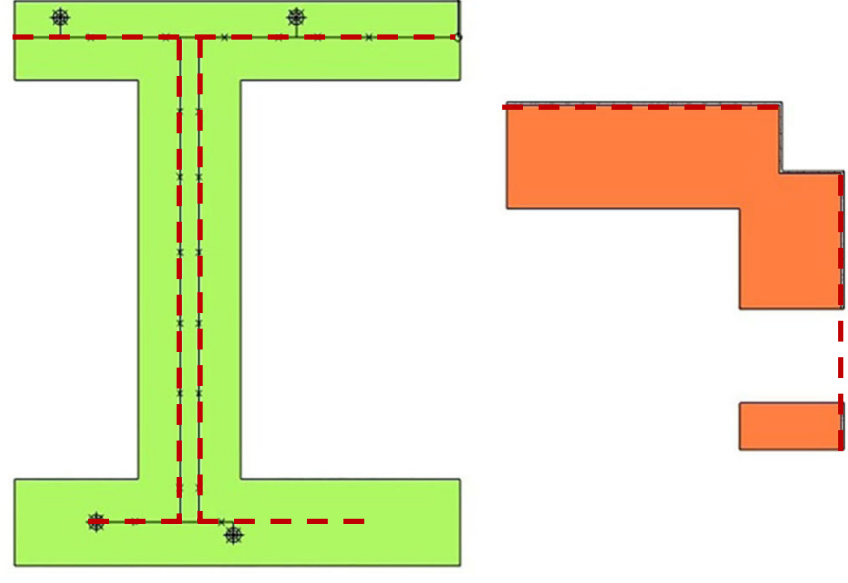

Fig. 1. The development of workspaces based on the building components axis

In this method, the spaces of building components were utilized separately from the workspaces of construction resources and their nature were different in terms of appearance. Therefore, they should be categorized in different groups in order to simulate activities in a correct way. Two kinds of activities can be defined in visual simulation software for appearance. These types of appearance in the simulation model should be in accordance with the nature of construction activities and their correspond resources. These definitions of the activities determine the way in which the volumes corresponding the activities appear in visual simulation software. Considering the micro level of the case study defined for the activities and the construction resources, both the permanent (construct) and temporary activities are applied.

Building components are of construct type during the simulation and were attributed to the corresponding activities with all of the volumes (3D components) that were permanent from the time of appearance to the end of simulation. This group includes building components and elements such as doors, windows, floors, walls and so on. The appearance of these activities in the beginning of the activity is as transparent volumes with green color and in the end of the activity the final 3D model of the building component appears and remains to the end. Because of breaking the building components down to one day's building components, these components were added daily and based on the schedule to the volumes and remain.

3D components related to the workspace were in temporary state and only appear in the time of activity performance in simulation. Temporary activities were corresponding to the construction resources in three categories of materials, machinery or equipment and manpower. For each of the resources, an attributed space was designed that covered the main resource in the form of transparent and geometric volumes. The workspace of the construction resource was defined to produce the building components of one day and it is appeared daily and continuously besides building components and is hidden in the end of that day. Actually, after the construction of one day's workspace were hidden and then the corresponding volumes with 3D building components were appeared and remained to the end.

\section{CONFLICT ANALYSIS OF BUILDING COMPONENTS AND CONSTRUCTION RESOURCES}

The most fundamental issue in the workspace planning is the dynamism and mobility of the available workspace. First, because different sub-contractors and working-teams occupy workspace in a similar way and lead to spatial conflicts. Second, the building components change the available space of the activity and generally these spaces become more restricted by the project progresses[18]. For instance, by constructing of interior walls, the available space of floor has changed and divided to smaller parts for other activities. The experienced planners consider the availability of workspaces based on the personal view in the projects, but it is not according to specific principles and mechanism. A distinctive feature of the construction projects which distinguishes it from other sector is the changing of workspace by passing time. While the spatial configuration of the manufacturing in factory has an emphasis in the equipment's layout and remains permanent and static in the space production [8].

The time-based conflicts creates integration of time-based simulation by clash detection method. Actually, permanent and temporary $3 \mathrm{D}$ volumes were appeared and disappeared based on the timeline of activities and on the specific location. Two or more volumes corresponding to the workspace and building components can occupy a specific space simultaneously and create clashes that lead to workspace conflicts. Launching the time-based clash detection examines the clashes automatically during the construction operation. Therefore, each clash is recorded and identified together with its time, coordination and the clash distance to enables the user for analyzing the project space situation.

Generally, the methods of detecting spatial clashes for the activities are in two forms. The first choice is the cross section method (hard) in which a test for the detection of geometric cross clash among volumes is conducted. In this case, a negligible distance is defined for the clash, so if the geometric clash distance is more than that distance, then a conflict is recorded. The second option is called the tolerable permission, in which a distance between two volumes is defined and any distance less than that is unpermitted. If the distance between two geometric volumes is more than the determined distance by the user, no spatial conflicts are recorded. For instance, facility pipes need space as insulation around them, which requires a minimum distance between these two volumes. In this regard, the three types of clashes were compared and analyzed using the hard mode and in various distances.

\section{A. Inflexible conflicts (3D components against each other)}

The clashes of building components with each other occur in conditions that the design is problematic and the permanent components are located and occupied in the same location [16]. These clashes are not investigated based on time and should be examined toughly and with geometric crosses, without any permitted distance. In a context that the 3D geometric models were derived from 2D space drawings and positioned on the specific axis from different disciplines, it is possible that occurs conflicts[19]. This problem can arise from some reasons such 
as miscalculations or the lack of awareness of other discipline changes.

In such cases, the design issue should be removed from all activities of projects and no clashes are acceptable. In the modeling of this research, nine activities were derived from three architectural, mechanical and electrical disciplines and based of $2 \mathrm{D}$ drawings. Then, these $2 \mathrm{D}$ construction documents were imported to Google Sketchup software to make the 3D models. These building components were examined in hard geometric clash detection with zero acceptable clash range, and the number of 316 geometric and design clashes were identified. By changing the acceptable distance of the clashes from 0 to 0.3 meter, the quantity of clashes reached from 316 to zero. The first case of clash in design was between Dropped ceiling and interior dry walls which is shown in Figure 2.

Also, the graph of clash quantity changes is presented in Table III with its acceptable changing range. In fact, the accuracy of the modeling contains $30 \mathrm{~cm}$ error which is not an acceptable distance for engineering design and multi-discipline layouts. According to the statistics, only $7.3 \%$ of the clashes (23 cases) have been continued in more than 0.1 meters, and were mainly caused by the vertical items like dry wall with suspended ceiling. The large number of remained clashes $(92.3 \%)$ were related to minor errors in the volume design that have not a great impact on the construction operation and can be resolved easily by design modifications.

TABLE III. SENSITIVY ANALYSIS OF INFLEXIBLE CONFLICTS IN DIFFERENT DISTANCE INTERVALS

\begin{tabular}{|c|c|c|c|c|c|}
\hline \multicolumn{6}{|c|}{ 3D Components against 3D Components } \\
(Hard type of clash detective on Non-Time-liner simulation) \\
\hline $\begin{array}{c}\text { Tolerance } \\
\text { Distance (m) }\end{array}$ & 0.3 & 0.25 & 0.20 & 0.10 & 0.00 \\
\hline Clash Numbers & 0 & 10 & 14 & 23 & 316 \\
\hline Percent & $0 \%$ & $3.2 \%$ & $4.4 \%$ & $7.3 \%$ & $100 \%$ \\
\hline
\end{tabular}

\section{B. Semi-flexible conflicts (3D components against $3 D$ workspaces)}

By the project progression and the creation of permanent building elements based on the schedule, the available workspace is affected especially in micro level construction. In fact, by the creation of building components, the workspace of the activities are restricted and new obstacles are created for the dynamic space of the construction resources. Actually, the dynamic volumes of the construction resources that correspond to the workspaces may have clashes with static building elements. Although, according to the construction requirements and the execution nature of activities, dependency and delays between these activities must be considered correctly and at the beginning of the planning by experts' planners, so that they do not prevent each other's operation. But the building component development can restrict the upcoming activity resources' workspace. For example, the activity of constructing the interior wall causes the breakdown of the floor space and the delay in construction of the next activities' space. These limitations do not make the other activities' execution and construction impossible, but make more difficulties and hinders for the movement of materials and human resources. So, minimizing these kind of clashes can be very effective by itself. The changing of these clashes according to tolerance distance are depicted in Table IV.

As it can be seen, only the building components of the three activities of 3,5 and 6 had clashes with the other construction workspaces with the distance of more than 0.1 meters. As predicted, most of the clashes were related to the construction of internal walls that occurred for distances up to 3 meters. After that, the building components of the external brick-laying activities and plastering that cover the surrounding operations of floor have made the most conflicts with other workspaces. The other clashes between 0 to 0.2 meter distances can resolved by increasing the accuracy of design and decreasing the overlap of the volumes. This minor interferences were negligible and they do not prevent the progress of the construction operation because of their slight quantity between the resource clashes (dynamic volumes) and permanent building components (static volumes). One of the examples of these spatial conflicts is presented in Figure 3. As shown in this figure, the $3 \mathrm{D}$ building components of dry wall have space conflict with 3D workspace of ceramic tiling activity. This clash was detected in visual simulation in wide ranges of tolerance distance.

\section{Flexible conflicts (3D workspaces with each other)}

The challenges of time-space conflicts analysis in construction projects include 3D spatial and temporal conflict detection. The temporary dimension of the time-space conflicts indicates that the spatial conflict detection among activities must include 3D geometric clashes in specific time intervals that shows the time aspect of these conflicts [13]. In addition, many kinds of time-space conflicts can occur between the activities and the quantity and intensity of them are varied. One simple 3D shape cannot be used to present the dynamism of the workspace in construction activities. In this regard, this study by breaking down the volumes related to the construction resources and assigning daily activities to them caused the dynamic and real presentation of work flow development. The activities related to the workspace volumes mutually were examined with other activities' workspace volumes in the visual simulation software to specify the spatial clashes. The geometric clash detection were performed in visual simulation software to record the cross section volumes corresponding to the workspaces with each other in the hard type and in the permitted distances of 0 to 3.5 meters. This test is presented in Table IV. From the information analysis and the visualization of clashes it can be concluded that in the range of 0 to 0.1 meters, the quantity of clashes are decreased to $49 \%$, which was mainly for the repeated or minor overlaps of the workspace. The conflicts of this range can be solved by a slight review and design of the spatial volumes. On the other hand, the clashes would not much change and in the real conditions it would be led to serious conflicts in the range of 0.1 to 2 meters. In this interval, the clashes have reached from 32 to 18 and they are mostly related to the workspace of the three activities of 3, 6 and 8 construction activities resources. The maximum workspace clashes are related to the ceramic flooring activity (8) which has conflicts with other workspaces such as fabricating of the suspended ceiling. 
TABLE IV. SENSITIVY ANALYSIS OF FLEXIBLE CONFLICTS IN DIFFERENT DISTANCE INTERVALS

\begin{tabular}{|c|c|c|c|c|c|c|c|c|c|c|c|c|c|c|c|c|}
\hline \multicolumn{17}{|c|}{ 3D WORKSPACES AGAINST 3D WORKSPACES (TIME-LINER HARD CONSERVATIVE) } \\
\hline Tolerance Distance (m) & 3.5 & 3 & 2.5 & 2 & 1.5 & 1 & 0.9 & 0.8 & 0.7 & 0.6 & 0.5 & 0.4 & 0.3 & 0.2 & 0.1 & 0 \\
\hline Act.3 Clashes & 0 & 2 & 2 & 3 & 3 & 4 & 4 & 5 & 7 & 7 & 7 & 7 & 7 & 7 & 7 & 10 \\
\hline Act.4 Clashes & 0 & 1 & 1 & 1 & 1 & 1 & 1 & 1 & 1 & 1 & 1 & 1 & 1 & 1 & 1 & 1 \\
\hline Act.6 Clashes & 0 & 0 & 0 & 0 & 1 & 2 & 2 & 2 & 2 & 3 & 3 & 3 & 3 & 3 & 3 & 4 \\
\hline Act.7 Clashes & 0 & 0 & 0 & 0 & 1 & 2 & 2 & 2 & 2 & 2 & 2 & 2 & 2 & 2 & 2 & 2 \\
\hline Act.8 Clashes & 0 & 0 & 6 & 14 & 14 & 15 & 16 & 16 & 16 & 16 & 17 & 18 & 18 & 18 & 25 & 58 \\
\hline Act.9 Clashes & 0 & 0 & 0 & 0 & 0 & 0 & 0 & 0 & 0 & 1 & 1 & 1 & 1 & 1 & 1 & 1 \\
\hline Act.10 Clashes & 0 & 0 & 0 & 0 & 0 & 0 & 0 & 0 & 0 & 0 & 0 & 0 & 0 & 0 & 0 & 0 \\
\hline Total Clash Numbers & 0 & 3 & 9 & 18 & 20 & 24 & 25 & 26 & 28 & 30 & 31 & 32 & 32 & 32 & 39 & 76 \\
\hline Percent & $0 \%$ & $4 \%$ & $12 \%$ & $24 \%$ & $26 \%$ & $32 \%$ & $33 \%$ & $34 \%$ & $37 \%$ & $39 \%$ & $41 \%$ & $42 \%$ & $42 \%$ & $42 \%$ & $51 \%$ & $100 \%$ \\
\hline
\end{tabular}

In 2 to 3 meters ranges, the number of conflicts decreased completely and reached to zero and does not provide an appropriate interval for the serious consideration of the workspace clashes. The clashes of workspaces with each other are temporary, related to time dimension and instead they are depended on the dynamic resources and can be solved by different strategies. One of the examples of these spatial conflicts is presented in Figure 4. As shown in this figure, the 3D workspaces required for installation of cable tray have time-space conflict with 3D workspace of plumping fan coil activity. This clash was detected in visual simulation in almost all ranges of tolerance distance which demonstrates its necessity situation.

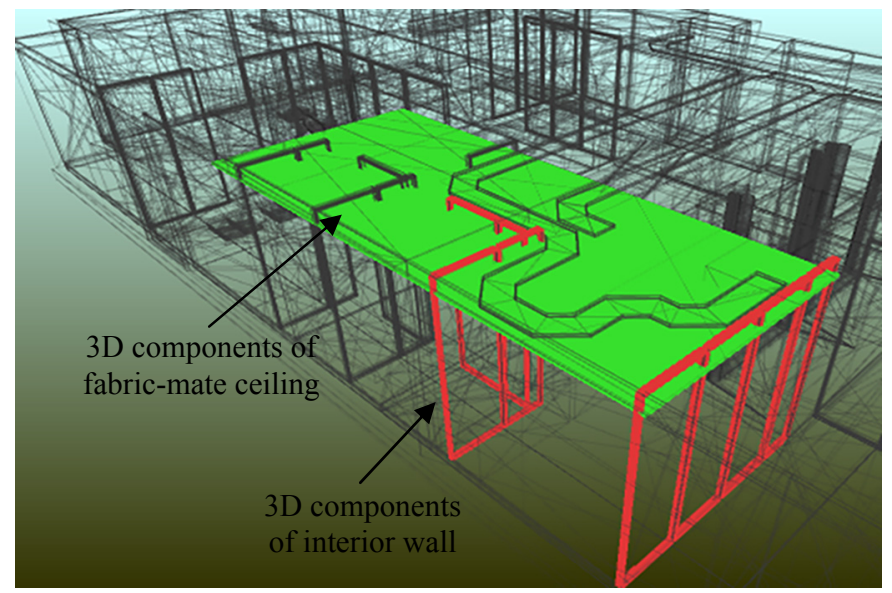

Fig. 2. A sample of building components design clashes

\section{RESULTS AND FINDINGS}

The number of conflicts were explored in three states of flexible, semi-flexible and rigid with clash ranges from 0 to 3.5 meters. The highest number of clashes was shown as $100 \%$ and the condition without any clashes was considered as $0 \%$ (Figure 5). Although in design clashes no permitted intervals were acceptable, but the main and the most important clashes that can be examined and be effective in the design process were related to 0.1 meters and further. The semi-flexible clashes between dynamic construction resources (workspaces) and static building components showed that the 0.2 to 1 meter intervals had a great impact on the project progression and must be solved. The clashes of flexible workspace with each other in 0.2 to 2 meter intervals were consistent and caused by the operation inconsistencies. In this interval, the number of conflicts were close and it is essential to solve them by using of conflict resolution strategies.

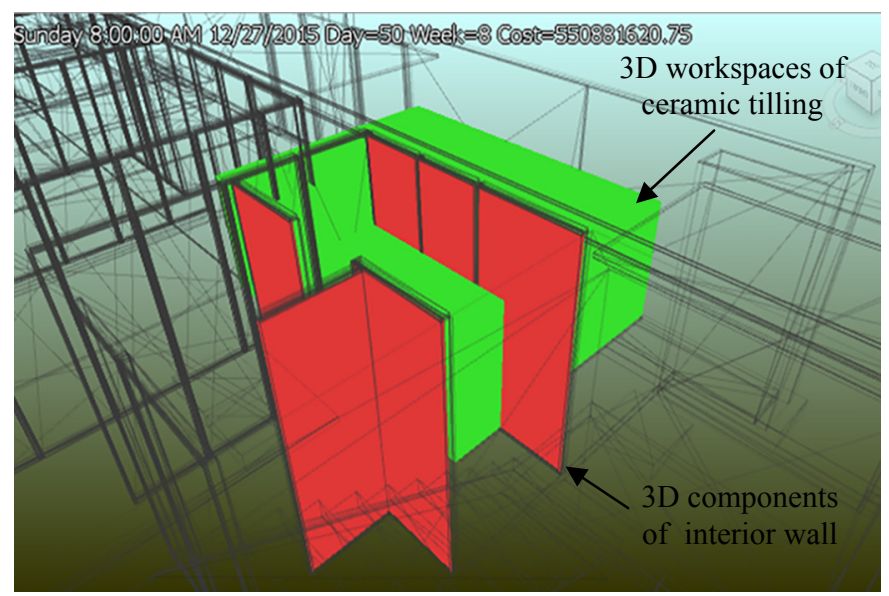

Fig. 3. A sample of flexible spatial conflict for workspaces.

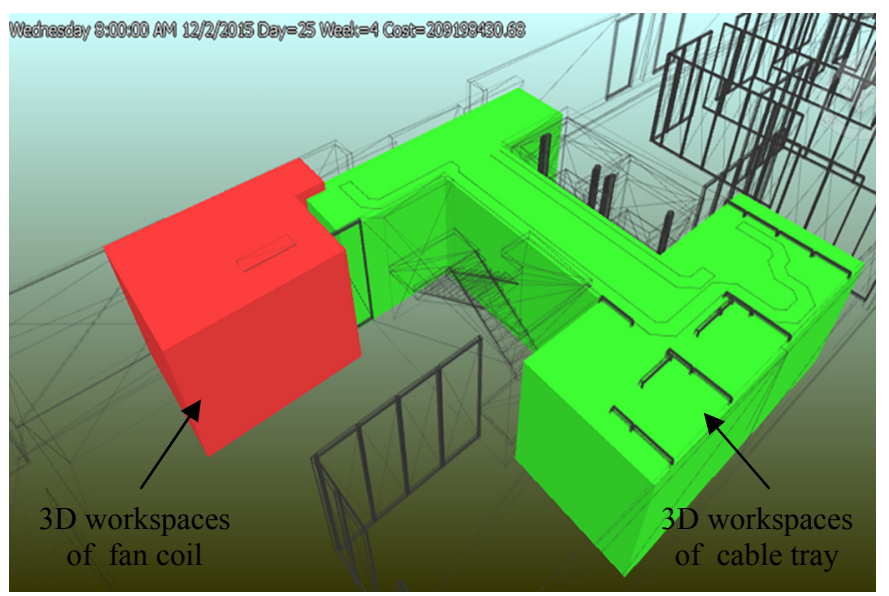

Fig. 4. A sample of flexible spatial conflict for workspaces

\section{CONCLUSION}

In the present study, the relation between the numbers of clashes in different modes according to the geometric condition was examined. To achieve this goal, after analyzing the 
construction activities and calculating the corresponding volume quantities for resources in each day, the building component and resource spaces were defined permanently and temporarily. The corresponding geometric volumes with these spaces were formed and generated in the 3D shape using building component axis and its daily quantity. Then, these 3D volumes were linked to the correspond activities in the timeline to visual simulation software. The 4D CAD model was simulated based on time in three statuses of building components with each other, workspaces with each other and the combination of workspaces and building components. Then, the time-based clashes of each category by different permitted distances were examined to determine the way of changing the number of clashes based on this condition changing. This system effectively helps designers and planners in finding the permitted range of volume clashes and can identify the clashes that affect the project progression and delay the project work flow.

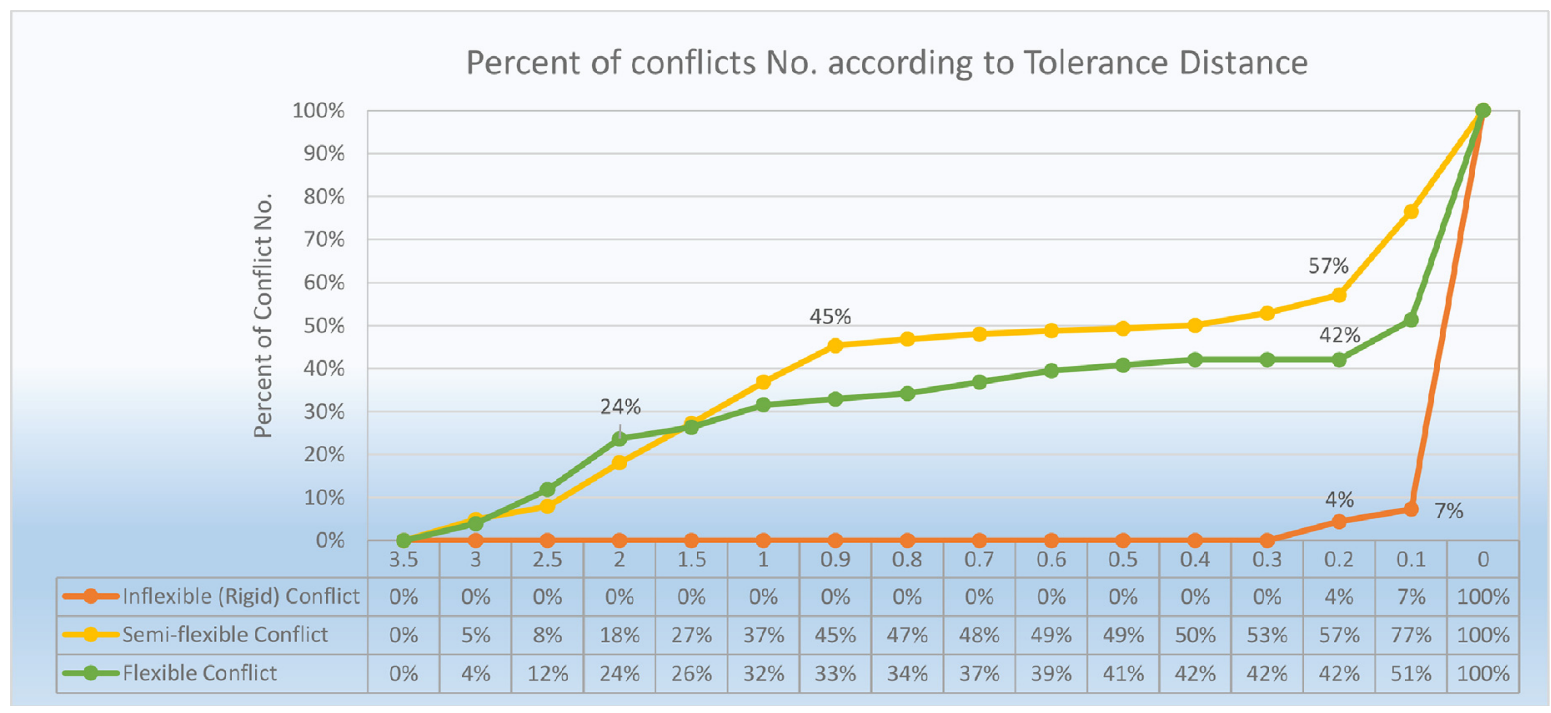

Fig. 5. The percent of clashes in three different modes and based on different permitted intervals

\section{REFERENCES}

[1] A. Mahalingam, R. Kashyap, C. Mahajan, "An evaluation of the applicability of 4D CAD on construction projects". Automation in Construction. Vol. 19, No. 2, pp. 148-159, 2010

[2] H. Moon, N. Dawood, L. Kang, "Development of workspace conflict visualization system using 4D object of work schedule". Advanced Engineering Informatics. Vol. 28, No. 1, pp. 50-65, 2014

[3] B. Koo, M. Fischer, "Feasibility Study of 4D CAD in Commercial Construction". Journal of Construction Engineering and Management. Vol. 126, No. 4, pp. 251-260, 2000

[4] B. Akinci, K. Tantisevi, E. Ergen, "Assessment of the Capabilities of a Commercial 4D CAD System to Visualize Equipment Space Requirements on Construction Sites", Construction Research Congress. p. $1-7,2003$

[5] K. Tantisevi, B. Akinci, "Automated generation of workspace requirements of mobile crane operations to support conflict detection", Automation in Construction, Vol. 16, No. 3, pp. 262-276, 2007

[6] X. Su, A spatial temporal information model for construction planning, Purdue University, 2013

[7] H. J. Wang, J. P. Zhang, K. W. A. Chau, "4D dynamic management for construction planning and resource utilization", Automation in Construction, Vol. 13, No. 5, pp. 575-589, 2004

[8] G. Winch, S. North, "Critical Space Analysis", Journal of Construction Engineering and Management, Vol. 132, No. 5, pp. 473-481, 2006

[9] T. Hartmann, J. Gao, M. Fischer, "Areas of Application for 3D and 4D Models on Construction Projects". Journal of Construction Engineering and Management, Vol. 134, No. 10, pp. 776-785, 2008
[10] M. Rohani, G. Shafabakhsh, A. Haddad, E. Asnaashari, "Operation Planning of Concrete Box Girder Bridge by 4D CAD Visualization Techniques", International Journal of Civil, Environmental, Structural, Construction and Architectural Engineering. Vol. 10, No. 6, pp. 790796, 2016

[11] V. C. Dixit. "4D Modeling: Adding a New Dimension to CPM Scheduling”, AACE International Transactions, 2007

[12] D. Heesom, An Analytical System for Space Planning on Construction Sites, University of Wolverhampton, 2004

[13] B. Akinci, M. Fischen, R. Levitt, R. Carlson, "Formalization and Automation of Time-Space Conflict Analysis", Journal of Computing in Civil Engineering, Vol. 16, No. 2, pp. 124-134, 2002

[14] R. Morkos, J. Macedo, M. Fischer, C. Somu, "Quantifying Effects of Specific 4D Tool Functionalities on 4D Modeling Productivity", Proceedings of the CIB W78, Beirut, Lebanon, 2012

[15] W. Thabet, Y. Beliveau, "Modeling Work Space to Schedule Repetitive Floors in Multistory Buildings", Journal of Construction Engineering and Management, Vol. 120, No. 1, pp. 96-116, 1994

[16] I. Chen Wu, Y. Chang Chiu, "4D Workspace Conflict Detection and Analysis System", Conference on Construction Applications of Virtual Reality, 2010

[17] M. Rohani, M. Fan, C. Yu, "Advanced visualization and simulation techniques for modern construction management", Indoor and Built Environment, Vol. 23, No. 5, pp. 665-674, 2014

[18] M. Kassem, N. Dawood, R. Chavada, "Construction workspace management within an Industry Foundation Class-Compliant 4D tool". Automation in Construction. Vol. 5, No. 2, pp. 42-58, 2015

[19] D. Riley, "The Role of 4D Modeling in Trade Sequencing and Production Planning", Construction Congress VI, pp. 1029-1034, 2000 